\title{
Analysis of the Influencing Factors of Migrant Worker Social Insurance in Lanzhou
}

\author{
Xiaoli Zong ${ }^{1}$, Xin Guan ${ }^{1 *}$, Yang Gao ${ }^{1}$, Zhanglei Chen ${ }^{1}$, Guoxing Zhang ${ }^{1}$ \\ ${ }^{1}$ School of Management, Lanzhou University, Lanzhou, CHINA
}

Received 7 May 2017 - Revised 20 August 2017 - Accepted 28 September 2017

\begin{abstract}
There is no clear answer in academic world about whether to establish a social security system for migrant worker, and if doing so, whether it will influence the enterprisescompetitiveness. Migrant worker has been contributing a lot for the urban construction, but it is also a vulnerable group, so the research in social security system for migrant worker is an inevitable problem. How to protect and guarantee the interests of the migrant workers become the social problem needed to be solved immediately nowadays. Based on the investigation about the situation of migrant worker's social insurance in Lanzhou and applying the Logistic regression model to analyze the influence factors of migrant worker's participation in social insurance in Lanzhou. This article proposes some suggestions about establishing a national electronic information files for migrant workers and transforming of the advertisement methods of the government.
\end{abstract}

Keywords: peasant-worker, social insurance, influence factor, logistic regression model, electronic information files

\section{INTRODUCTION}

With the constant development of industrialization and urbanization of our country, the urban-rural dual structure has been adjusted continuously. More and more migrant workers have crowded into city and try to integrate with citizens, being the new social group in the process of urbanization. According to the sampling survey by the State Statistical Bureau, there are 2.7747 billion migrant workers in 2015, increasing 3.52 million compared with last year, the growth rate is $1.3 \%$. Migrant workers contribute a lot for the construction of the urbanization; they promote the economy development of the city and devote themselves for the economy growth of the country. But at the same time, they bring a series of social problems. Since migrant workers are in the weak position in the employeremployee relationship and they lack the necessary sense of safeguarding legal rights; moreover, due to the faultiness of the system, migrant workers are still in the margin of the development of the urbanization, they still can't be identified and shared the welfare of the social insurance. Some scholars have pointed out: "The solution of the social insurance of the migrant workers are directly related to the vital interests of the migrant workers, the fairness of the society, the long period of stability of the country under the new situation. The existing problems need to be solved immediately."

The social security of migrant workers are not only related to the vital interests of the migrant workers, but also related to the stability and development of the society. It's the important contentment of the construction of the harmonious society of the socialism. In November $2005,<$ Notice on improving the employment and reemployment from the State Council> points out that "we should positively provide migrant workers with necessary social security"; in January 2006, <Some opinions on solving the problems of migrant workers from the State Council> emphasize that "we should positively and prudently solve the social security problems of the migrant workers, legally bring migrant worker into the scope of the employment injury insurance and find out the suitable endowment insurance for migrant worker"; On March 5th, 2006, Premier Wen have clearly pointed out in the government work report that:" we should study the social security measures that is suitable for migrant worker"; the Central Committee of the Communist Party of China formulates <the suggestion on the 11th five-year plan of

(C) Authors. Terms and conditions of Creative Commons Attribution 4.0 International (CC BY 4.0) apply. 


\section{Contribution of this paper to the literature}

- Individual factor will affect one's decision, including age, gender, education, marital status and so on. The greatest influence among these factors is education.

- Influencing factors in unit level are industry types, sign the labor contract, and clerk and so on. Individual level, factors in unit level have the greater influence in migrant worker's choice. It reflects that in market economy, unit's supply willingness will greatly influence migrant worker's participation.

- In Legal system level, such as the sources, understanding level and so on. The sources and other factors will influence migrant worker's choice in participating in social insurance in Lanzhou, the more regular

- The Seriousness of the application of current social security system, the low insured rate of social insurance reflects the insufficiency of the system design, the coverage, and the propaganda, so it block the sources.

the national economy and social development> and clearly proposes that:" we should seriously solve the social security problem of the migrant workers".

It marks that the social security of the migrant worker have been officially brought into the government work schedule and caused highly focus. On October 28th, 2010, with the publishment and application of the < Social Security Act of People's Republic of China>, it marks the legal period of the social security system. But during the application of the social security work, the coverage of the social insurance in migrant workers is still in a lower level; besides, migrant workers are mostly concentrate on some single insurance type. How to protect the fied rights of the migrant worker to achieve the harmony and stability of the society has been the vital subject in current society.

\section{LITERATURE REVIEW}

The domestic academic world has carried on some in-depth studies on social security problem and achieved some valuable research findings. It mainly researches on the division of the research stage of the migrant workers participating in social insurance, the significance and countermeasures of constructing social security system of the migrant worker, the factors of migrant workers participating in social insurance and other perspectives. At different stages of economic development, there exists a bigger difference of migrant workers participating in social insurance. Zheng Hangsheng and Wu Dawei (1994) emphasizes that we should develop the social insurance system that is suitable for migrant workers. Luo Rong and Luo Peng take Cheng Du as an example to study on the design of the social insurance system. They conclude the existing problems into four parts: First, the design of the insurance type can't reflect the insured person's willingness, so it lacks the attraction for migrant workers. Second, the charge standard such as industrial injury isn't reasonable enough. Third, when the comprehensive insurance transform into the basic insurance, it may increase the risk of fund. Fourth, the higher human resource cost may influence the positivity of insured person. After that, more researches are focus on the existing problems on the process of implying social insurance and the reason of the lagging. Some scholars start with the system, they consider the constant social security system are not properly combined with the features of migrant worker, so it resulted in the tediousness of the procedure and the limitation of the scope. The migrant worker can't imply under the current system, so the degree of participation is low; other scholars try to analyze this problem during the process of application, they think that the executing agency and supervision agency don't carry out their work completely, they don't supervise enterprises to buy social insurance for migrant workers; moreover, our country is short of the relating laws and regulations and not strictly punish the enterprises which isn't buy relevant insurance for migrant workers; for example, Peng Zhaiwen (2005) consider that due to the exclusiveness of social welfare and social assistance, there are few national policies and fewer intensive study about it. Some other scholars think that migrant worker haven't establish the sense of participating in the social insurance, they don't know much about it, so the positivity of migrant worker are not as high as expected (Fei et al., 2013; Wei, 2013; Nan, 2010; Jiaojiao, 2012; Ning, 2013; Park et al., 2016).

When the research on participation in social insurance of migrant workers are growing, on the basis of this, some scholars propose to construct social security system for migrant workers. Luo Zhixian (2005) thinks that sound social security system can rapidly achieve the transformation of the social structure and improvement of the urbanization level. It not only favor for the consideration of social fairness and economy efficiency, but also favor for building legal state of socialism. Wang Tao (2005) believe that social security issue of migrant worker are not only relevant with maintenance of rights, but also relevant with the achievement of urbanization of countryside and entire construction of affluent society. Zhou Yiqiao (2004) believe that we should eliminate the current institutional discrimination existed in social security system and laws; improve the measures of legislation and judicial to clear and definite the guaranteed objects, fund raise, standard, management and so on; meanwhile we should strengthen the building of social security organization, and improve the management and supervise system of social security of migrant worker for migrant workers. Other than that, constructing personal development 
accounts, achieving the ideas of institutionalized assets constructed by the society can also be used for reference to solve the problems.

But as the vulnerable group of the society, the living standard and quality can't be guaranteed for a long time. The reasons may lie in the following aspects: the imbalance of the development of society and economy; the imperfection of the construction of corresponding social system; the influence of the income and education level of migrant workers. Thus, the first job to promote the perfect and develop the construction of social security system is to analyze the influencing factors of migrant workers' participation in social insurance and carry forward the construction of social security system. On the research of the influencing factors, Hu Yangti's (2009) research completely explains that a single factor has different functions in different types of insurances, so it's necessary to make regression traits separately according to typical insurance; $\mathrm{Zhu} \mathrm{Li}$, Wu Wei (2012) based on the regression analysis from the research of factors of migrant workers' participating in social insurance in Jiangsu Province, the result explains that individual traits take effect in the process of participating in social insurance, and the rate of participating insurance in female is higher than male in the result of first study; Liu Jinfei, Zheng Shengping (2013) introduce social inclusion theory applied abroad to study on the Cainozoic migrant workers' willingness and influencing factors of participating in social insurance, they validate and analyze the influencing factors in economic integration, social integration and culture psychology integration. GuYonghong (2010) carries on an empirical analysis on migrant workers' willingness in participating in social insurance. She starts from their willingness, applying Logit regression model to validate its hypothesis. Huang Ningyang, Gong Meng base the study on migration theory, utilize the date on the research of farmer and Logit model to do quantitative analysis. They find that unit character have an effect on trans-provincial transfer. Xu Zengyang, Ji Shengxiang (2014) and Cai He thinks that profession, being deprived and gender have the strongest function in non-institutional tendency to safeguard legal rights of migrant workers. On the research of vulnerable group's participating in medical insurance by Li Jia and Lu Xuejing (2013), according to the maximin principle from Rolls, they divided the influencing factors into four types, applying Probit model to analyze and find out that there exists few discrimination to vulnerable group among the personal reasons; for the physical condition of interviewees, physical situation doesn't have an apparent adverse selection effect; there exist huge differences among different areas.

In summary, the construction and research on migrant worker's social security system still need to be improved, especially in following aspects: first, the coverage is insufficient. The research mainly focuses on eastern coastal area, but a few focuses on under-developed area on the north-western part of China; second, the research area is imbalance. Current research has two tendencies: first, study on separate insurance, such as endowment insurance or employment injury insurance, but seldom study on other types of insurance; the other tendency is study the five insurances as a whole, but including an aggregate variable into the statistical analysis can't avoid the mutual interference among different types of insurance and make the result partially.

This article based on the investigation and research on harmonious labor relation in minor enterprises in Gansu Province, analyze the important factors affecting migrant worker's participation in social insurance and make regression analysis separately. At the same time, we unite the research results and put forward some suggestions for improvement to provide references for relevant departments formulating all-pervading social insurance policy, enrich the study on the present situation on migrant workers' social insurance, improve the coverage of social insurance among migrant workers, guarantee the legal interests of migrant workers, relieve social contradictions and promote the harmony and development of the society.

\section{THE ANALYSIS OF MIGRANT WORKERS' PARTICIPATION IN SOCIAL INSURANCE IN LANZHOU}

\section{Research Object}

This research takes the pattern of sending out questionnaire and make sampling survey on migrant workers in Lanzhou. The questionnaire mainly involves the base situation and relevant situation on participation on social insurance of migrant workers. The total number of this sampling survey is 182, male takes up 79 and female takes up 103. The age 35 and below occupy $46.9 \%$, 35-45 occupy 31\%, 45-55 occupy 16.7\%, 55 and above occupy $4.2 \%$. The education level in primary school and below occupy $20.3 \%$, junior middle school occupy $45.6 \%$, and high school occupy $23.6 \%$, college and above occupy $10.4 \%$. On marital status, unmarried people take up $71.9 \%$ and married take up $28.6 \%$. Individual monthly income below 500 occupy $2.7 \%, 500-1000$ occupy $9.9 \%, 1000-1500$ occupy $38.5 \%$, $1500-2000$ occupy $9.9 \%, 2000-2500$ occupy $15.9 \%, 2500-3000$ occupy $13.7 \%, 3500$ and above occupy $3.8 \%$. 
Table 1. Data statistics

\begin{tabular}{|c|c|c|c|c|c|c|c|c|c|c|}
\hline \multirow[t]{2}{*}{ Information } & & \multicolumn{2}{|c|}{ Chengguan District } & \multicolumn{2}{|c|}{ Xigu District } & \multicolumn{2}{|c|}{ Anning District } & \multicolumn{2}{|c|}{ Qilihe District } & \multirow[t]{2}{*}{ Total } \\
\hline & & Number & Percentage & Number & Percentage & Number & Percentage & Number & Percentage & \\
\hline \multirow[t]{2}{*}{ Gender } & Female & 41 & 56.9 & 31 & 56.4 & 16 & 57.1 & 15 & 55.6 & 103 \\
\hline & Male & 31 & 43.1 & 24 & 43.6 & 12 & 42.9 & 12 & 44.4 & 79 \\
\hline \multirow{4}{*}{ Age } & $y \leq 35$ & 34 & 39.5 & 26 & 30.2 & 12 & 14.0 & 14 & 16.3 & 86 \\
\hline & $35<y \leq 45$ & 22 & 38.6 & 17 & 29.8 & 8 & 14.0 & 10 & 17.6 & 57 \\
\hline & $45<y \leq 55$ & 12 & 38.7 & 9 & 29.0 & 4 & 12.9 & 6 & 19.4 & 31 \\
\hline & $y>55$ & 3 & 37.5 & 3 & 37.5 & 1 & 12.5 & 1 & 12.5 & 8 \\
\hline \multirow{4}{*}{ Education } & $\begin{array}{c}\text { Primary and } \\
\text { below }\end{array}$ & 15 & 40.5 & 11 & 29.7 & 6 & 16.2 & 5 & 13.6 & 37 \\
\hline & Junior high & 33 & 39.8 & 25 & 30.1 & 13 & 15.6 & 12 & 14.5 & 83 \\
\hline & $\begin{array}{l}\text { High school } \\
\text { and above }\end{array}$ & 17 & 39.5 & 13 & 30.2 & 6 & 14.0 & 7 & 16.3 & 43 \\
\hline & $\begin{array}{c}\text { Vocational } \\
\text { school and } \\
\text { above }\end{array}$ & 8 & 42.1 & 5 & 26.3 & 2 & 10.5 & 4 & 44.4 & 19 \\
\hline \multirow{2}{*}{$\begin{array}{l}\text { Marital } \\
\text { status }\end{array}$} & Unmarried & 52 & 40 & 39 & 30 & 18 & 13.8 & 21 & 16.2 & 130 \\
\hline & Married & 21 & 40.4 & 15 & 28.8 & 7 & 13.5 & 9 & 17.3 & 52 \\
\hline \multirow{8}{*}{$\begin{array}{l}\text { Personal } \\
\text { monthly } \\
\text { income }\end{array}$} & $y \leq 500$ & 2 & 40 & 1 & 20 & 2 & 40 & 0 & 0 & 5 \\
\hline & $500<y \leq 1000$ & 7 & 38.9 & 6 & 33.3 & 2 & 11.1 & 3 & 16.7 & 18 \\
\hline & $1000<y \leq 1500$ & 29 & 41.4 & 21 & 30 & 11 & 15.7 & 9 & 12.9 & 70 \\
\hline & $1500<y \leq 2000$ & 7 & 38.9 & 5 & 27.8 & 3 & 16.7 & 3 & 16.6 & 18 \\
\hline & $2000<y \leq 2500$ & 11 & 37.9 & 9 & 31.1 & 5 & 17.2 & 4 & 13.8 & 29 \\
\hline & $2500<y \leq 3000$ & 9 & 36.0 & 8 & 32 & 4 & 16 & 4 & 16 & 25 \\
\hline & $3000<y \leq 3500$ & 4 & 40 & 2 & 20 & 1 & 10 & 3 & 30 & 10 \\
\hline & $y>3500$ & 2 & 28.6 & 2 & 28.5 & 1 & 14.3 & 2 & 28.6 & 7 \\
\hline
\end{tabular}

\section{The Current Situation of Migrant Worker's Participation in Social Insurance in Lanzhou}

From the frequency and percentage of different insurances of data sorting, we can find out that the number of people participating in medical insurance is the most, taking up $57.1 \%$; the second is endowment insurance, taking up $46.7 \%$, the percentage of these two insurances are higher than other insurances. Unemployment insurance and employment injury insurance are lower. The analysis reasons are as following: (I). The backward of migrant workers' concept result in the low participation in these two insurances, most of the migrant worker don't have the concept of "unemployment" or their concept is weak; (II). Since employment injury insurance is mostly needed by migrant workers occupying in construction industry, and they have the feature of great mobility, the engineering project are always being contracted frequently. Theses objective conditions are adverse to migrant worker participating in employment injury insurance. In general, compared with the percentage published in China's monitoring survey on migrant worker in 2013, the coverage of migrant worker participating in endowment insurance, employment injury insurance, medical insurance, unemployment insurance and maternity insurance has been improved, but it still remains several problems, for example, the percentage of migrant workers participating in employment injury insurance is lower in Lanzhou. On the process of analyzing the results, we compare and analyze the male and female migrant workers' condition.

From the chart we can find that, the percentage of male and female migrant workers participating in each insurance are basically consistent, it reflects the great attention attached in traditional social status difference between male and female. As the vulnerable group of the society, the vital interests of female migrant workers are easier to be ignored, fortunately with the improvement of attention to women, the status of female migrant workers have also been improved, the legal rights of female migrant workers have also been better guaranteed. 
Table 2. Insured Situation

\begin{tabular}{|c|c|c|c|c|c|c|}
\hline \multirow{3}{*}{ Types } & \multicolumn{4}{|c|}{ Gender } & \multirow{3}{*}{ Sum } & \multirow{3}{*}{$\begin{array}{c}\text { Percentage } \\
\quad(\%)\end{array}$} \\
\hline & \multicolumn{2}{|r|}{ Female } & \multicolumn{2}{|r|}{ Male } & & \\
\hline & Sum & Percentage (\%) & Sum & Percentage (\%) & & \\
\hline Employment injury insurance & 14 & 13.6 & 16 & 20.3 & 30 & 16.5 \\
\hline Endowment insurance & 50 & 48.5 & 35 & 44.3 & 85 & 46.7 \\
\hline Unemployment insurance & 8 & 7.8 & 9 & 11.4 & 17 & 9.3 \\
\hline Maternity insurance & 23 & 22.3 & 18 & 22.8 & 41 & 22.5 \\
\hline Medical insurance & 60 & 58.3 & 44 & 55.7 & 104 & 57.1 \\
\hline
\end{tabular}

\section{The Understanding and Identification to Social Insurance of Migrant Worker in Lanzhou}

The degree of understanding about social insurance directly relating to the attitude they hold to the social insurance, the higher degree they know, the better social insurance they may choose to achieve guaranteeing their lawful rights.

The result shows that the degree of understanding of migrant workers in Lanzhou stays in the situation of slightly or commonly understand, only $5 \%$ of migrant workers understand it totally. In relevant interview, most of the migrant workers understand the social insurance superficially, they don't know much about how to pay the fees, the benefits and other deep-seated situation, neither some relevant regulations nor measures. At the same time, they just know the social insurance by "heard from others", "propaganda by government agencies", "propaganda by the social media and the Internet".

On the analysis of data sorting ,we can come with conclusion that "don't understand completely" and "heard from others" takes up 71.4\%, in "completely understand", "propaganda by government agencies" takes up 66.7\%, and with the degree of understanding goes deepen, the percentage of "heard from others" decrease, and "propaganda by government agencies" increase, at the same time "propaganda by unit" concentrate between "slightly understand" and "understand", "propaganda by social media and the Internet" is also concentrate on this scale. Migrant workers have the highest identification on propaganda by government agencies; the second is by social media, the Internet and the unit, but the audience of unit is smaller than the former one; "heard from others" have the lowest credibility, migrant workers also have the low identification on this source, but it's the extensive source.

\section{THE CHARACTERIZATION AND ANALYSIS OF INFLUENCING FACTORS}

\section{Evaluate the Variables and Logistic Regression Model}

The key point of this article lies in the discussion of influencing factors affecting migrant workers' participation in social insurance, we choose "participate or not participate" every single insurance as the dependent variable and investigate the influence of selected factors to every insurance. We evaluate " 1 " if subjects participate the insurance, if not, we evaluate " 0 ". The evaluation conditions are as following: 
Table 3. The types, valuation and distribution of the explain variables (\%)

\begin{tabular}{|c|c|c|c|}
\hline Explain variables & Variable types & Variable value & distribution (\%) \\
\hline \multirow{2}{*}{ Gender } & \multirow{2}{*}{ Classification variables } & $1=" \mathrm{male}^{\prime \prime}$ & 43.4 \\
\hline & & $0="$ female" & 56.6 \\
\hline Age & Range variables & & \\
\hline \multirow{4}{*}{ Education } & \multirow{4}{*}{ Order variables } & $1=$ "primary school and below" & 20.3 \\
\hline & & $2=$ "junior high school" & 45.6 \\
\hline & & $3=$ "high school" & 23.6 \\
\hline & & $4="$ vocational school and above" & 10.4 \\
\hline \multirow{2}{*}{ Marriage } & \multirow{2}{*}{ Classification variables } & $1="$ married" & 28.6 \\
\hline & & $0=$ "unmarried" & 71.4 \\
\hline \multirow{2}{*}{ Staff } & \multirow{2}{*}{ Classification variables } & $1=" y e s "$ & 41.8 \\
\hline & & $0="$ no" & 58.2 \\
\hline \multirow{8}{*}{ Personal monthly income } & \multirow{8}{*}{ Order variables } & $1=" y \leq 500 "$ & 2.7 \\
\hline & & $2=" 500<y \leq 1000 "$ & 9.9 \\
\hline & & $3=" 1000<y \leq 1500 "$ & 38.5 \\
\hline & & $4=" 1500<y \leq 2000 "$ & 9.9 \\
\hline & & $5=" 2000<y \leq 2500 "$ & 15.9 \\
\hline & & $6=" 2500<y \leq 3000 "$ & 13.7 \\
\hline & & $7=" 3000<y \leq 3500 "$ & 5.5 \\
\hline & & $8=" y>3500 "$ & 3.8 \\
\hline \multirow{5}{*}{ Level of understanding } & \multirow{5}{*}{ Order variables } & $1=$ "completely don't understand" & 11 \\
\hline & & $2=$ "slightly understand" & 38 \\
\hline & & $3="$ generally understand" & 33 \\
\hline & & $4=$ "understand" & 13 \\
\hline & & $5=$ "completely understand" & 5 \\
\hline \multirow{2}{*}{ Employment contract } & \multirow{2}{*}{ Classification variables } & $1=$ "assign" & 33.5 \\
\hline & & $0="$ no" & 66.5 \\
\hline \multirow{2}{*}{ Management } & \multirow{2}{*}{ Classification variables } & $1=" y e s "$ & 9.3 \\
\hline & & $0=" n o "$ & 90.7 \\
\hline \multirow{5}{*}{ Financial burden } & \multirow{5}{*}{ Order variables } & $1=$ "very slight" & 6.0 \\
\hline & & 2="slight" & 11.5 \\
\hline & & $3="$ general" & 63.7 \\
\hline & & $4=$ "heavy" & 7.7 \\
\hline & & $5=$ "very hevey" & 11.0 \\
\hline \multirow{4}{*}{ Occupation } & \multirow{4}{*}{ Classification variables } & $1="$ construction" & 8.8 \\
\hline & & $2=$ "services" & 77.5 \\
\hline & & $3="$ manufacturing" & 1.6 \\
\hline & & 4="others" & 12.1 \\
\hline \multirow{5}{*}{ Sources of understanding } & \multirow{5}{*}{ Classification variables } & $1="$ government propaganda" & 19.8 \\
\hline & & $2=" I n t e r n e t$ and media" & 23.6 \\
\hline & & $3=$ "company propaganda" & 10.4 \\
\hline & & $4=$ "heard from others" & 23.1 \\
\hline & & $5=$ "never heard about" & 23.1 \\
\hline \multirow{6}{*}{ Worries } & & $1=$ "work accident" & 3.3 \\
\hline & & $2=$ "unemployment" & 19.8 \\
\hline & & $3="$ nursing" & 17.6 \\
\hline & Classification variables & $4=" i l l n e s s "$ & 22.5 \\
\hline & & $5=$ "can't afford the tuition fees" & 17.0 \\
\hline & & $6=$ "others" & 19.8 \\
\hline
\end{tabular}

\section{The Analysis of Logistic Regression Model}

This article introduces 13 variables into the model and carry on the analysis. In these 13 explanatory variables, "profession", "source" and "worries" belong to classified variable, we set the top level as reference. The result is as following: 
Table 4. Regression analysis of employment injury insurance

\begin{tabular}{|c|c|c|c|c|}
\hline Explanatory variable & Regression coefficient (B) & Standard error (S.E.) & Significance (Sig.) & Power (Exp (B)) \\
\hline \multicolumn{5}{|l|}{ Employment injury insurance } \\
\hline Gender & .557 & .416 & .181 & 1.745 \\
\hline Age & -.010 & .023 & .680 & .990 \\
\hline Education & .372 & .236 & .115 & 1.450 \\
\hline Marital status & -.124 & .537 & .817 & .883 \\
\hline Clerk & .073 & .806 & .928 & 1.075 \\
\hline Monthly income & -.028 & .154 & .855 & .972 \\
\hline Understanding level & .848 & .257 & .001 & 2.334 \\
\hline Labor contract & 1.291 & .774 & .095 & 3.636 \\
\hline Management & -.099 & .676 & .884 & .906 \\
\hline Financial burden & -.217 & .246 & .378 & .805 \\
\hline Profession & & & .009 & \\
\hline Profession (1) & -2.801 & 1.327 & .035 & .061 \\
\hline Profession (2) & -3.056 & .898 & .001 & .047 \\
\hline Source & & & .115 & \\
\hline Worries & & & .044 & \\
\hline Worries (1) & 4.010 & 1.398 & .004 & 55.125 \\
\hline
\end{tabular}

\section{Analysis of employment injury insurance}

We can see from the Table 4 that, "understanding level", "worries (1)" and "profession (2)" pass the significance test of 0.01 level, the first two coefficients are positive, and the latter one is negative; besides, "labor contract" pass the significance test of 0.05 level, its coefficient is negative. "Worries (1)" refers to the most worrying problem of migrant workers in recent period is suffering employment injury; "profession (1)" refers to professions of these respondents is construction industry. Generally, the percentage of migrant workers participating in employment injury insurance is much higher than other industries, in other word, these two variables should have positive correlation, but the analysis result is opposite, the reason may be as following: (1) the mobility of those migrant workers is high, so it's difficult for them to participate in this insurance; (2) most of the migrant workers work in the construction plant, while such works are always be contracted, the relationship between employer and employee is always one-time and temporary, so migrant workers can hardly participate in employment injury insurance.

The people's bureau of the state of Lanzhou has carried out a research on the situation of construction migrant workers' participation in employment injury insurance since 2015, according to the statistics, there are 143.6 thousand construction employees in Lanzhou, who have stable labor relation take up 59 thousand, there are 34 thousand construction migrant workers participate in employment injury insurance until now, taking up 57.63\% of the total migrant workers who have stable labor relationship, taking up $23.7 \%$ of the construction employees of the whole city, we can find out that the rate of coverage of employment injury insurance still need to be improved, especially for the migrant workers whose labor relationship is comparatively loose.

"Profession (2)" refers to migrant workers working in service industry. Since it's difficult for migrant workers to suffer employment injury in service industry relatively, besides migrant workers are always working in individual business or enterprises, they usually don't care about whether they have this insurance or not, employer will not even purchase employment injury insurance for migrant workers, so these two variables have negative correlation. All in all, the improper supervision and nonstandard of different industries hinder migrant workers to safeguard their fied rights.

\section{Analysis of endowment insurance}

From the data analysis of Table 5, we can find that "understanding level", "labor contract" both pass the significance test of 0.05 level, their coefficient is both positive; "education" pass the significance test of 0.1 level, the coefficient is positive; besides, "sources" also pass the significance test of 0.05 level, the coefficient is positive. Fettered by traditional thinking, the understanding of endowment and social endowment implemented nowadays have a big difference, especially migrant workers lack of awareness about endowment issue. In the research result, we can find that "education", "understanding level" and "sources" both pass the significance test, the higher the education is, the more deeper the understanding level is, the sources have more credibility, the migrant workers are more willing to accept the endowment insurance policy; the more attention they attach to, the easier they participate in endowment insurance. To a certain extent, signing labor contract is a way of "forcing" migrant 
Table 5. Regression analysis of endowment insurance

\begin{tabular}{ccccc}
\hline Explanatory variable & Regression coefficient(B) & Standard error(S.E.) & Significance(sig.) & Power(exp(B)) \\
\hline Endowment insurance & & & & .688 \\
\hline Gender & -.128 & .319 & .353 & 1.017 \\
\hline Age & .016 & .018 & .053 & 1.429 \\
\hline Education & .357 & .185 & .196 & .575 \\
\hline Marital status & -.554 & .429 & .415 & .623 \\
\hline Clerk & -.473 & .581 & .549 & 1.066 \\
\hline Monthly income & .064 & .106 & .027 & 1.549 \\
\hline Understanding level & .438 & .198 & .047 & 3.265 \\
\hline Labor contract & 1.183 & .595 & .618 & 1.389 \\
\hline Management & .328 & .658 & .601 & 3.097 \\
\hline Financial burden & .093 & .177 & .067 & 33.969 \\
\hline Profession & & & .016 & 3.750 \\
\hline Profession (3) & 3.525 & 1.470 & .005 & 6.449 \\
\hline Sources & & .038 & 9.287 \\
\hline Sources (1) & 1.322 & .613 & .002 & \\
\hline Sources (2) & 1.864 & .772 & .004 & \\
\hline Sources (3) & 2.229 & & .416 & \\
\hline Worries & & &
\end{tabular}

Table 6. Regression analysis of unemployment insurance

\begin{tabular}{|c|c|c|c|c|}
\hline Explanatory variable & Regression coefficient(B) & Standard error(S.E.) & Significance(sig.) & Power(exp(B)) \\
\hline \multicolumn{5}{|l|}{ Unemployment insurance } \\
\hline Gender & .505 & .531 & .341 & 1.657 \\
\hline Age & -.003 & .030 & .915 & .997 \\
\hline Education & .707 & .317 & .026 & 2.029 \\
\hline Marital status & -1.199 & .775 & .122 & .302 \\
\hline Clerk & 2.749 & 1.069 & .010 & 15.625 \\
\hline Monthly income & .261 & .220 & .236 & 1.298 \\
\hline Understanding level & 1.028 & .345 & .003 & 2.796 \\
\hline Labor contract & -.112 & .820 & .892 & .894 \\
\hline Management & -1.409 & .903 & .118 & .244 \\
\hline Financial burden & -.485 & .333 & .145 & .616 \\
\hline Profession & & & .097 & \\
\hline Profession (3) & 10.185 & 4.225 & .016 & 26511.392 \\
\hline Sources & & & .161 & \\
\hline Sources (1) & 10.615 & 5.187 & .041 & 40757.990 \\
\hline Sources (2) & 8.944 & 4.900 & .068 & 7665.254 \\
\hline Sources (3) & 12.673 & 5.547 & .022 & 319152.633 \\
\hline Sources (4) & 10.066 & 4.799 & .036 & 23539.958 \\
\hline Worries & & & .251 & \\
\hline Worries (3) & -6.099 & 3.280 & .063 & .002 \\
\hline Worries (4) & -4.470 & 2.679 & .095 & .011 \\
\hline Worries (5) & -6.998 & 2.903 & .016 & .001 \\
\hline
\end{tabular}

workers buying endowment insurance, it's a way of protecting migrant worker's fied rights by system design and administrative power.

\section{Analysis of unemployment insurance}

From the data analysis of Table 6 we can find that "understanding level" pass the significance test of 0.01 level, the coefficient is positive; "clerk" and "education" both pass the significance of 0.05 level, their coefficient is positive; other three variables all pass the significance test of 0.05 level.

We analyze that clerk attach great importance to their work, since they live in downtown area, salary is the main income source, so losing job is equivalent to losing finance source; while migrant workers who are not clerk in the enterprises, they lack of the concept of unemployment, the mobility of their jobs is higher, so they are not very interested in unemployment insurance. From the analysis of "education" we can find that, clerk always have higher education than non-clerk, so these two variables have the same result in the analysis of unemployment 
Table 7. Regression analysis of maternity insurance

\begin{tabular}{ccccc}
\hline Explanatory variable & Regression coefficient(B) & Standard error(S.E.) & Significance(Sig.) & Power(Exp (B)) \\
\hline Maternity insurance & & & & .982 \\
\hline Gender & .009 & .390 & .475 & 1.009 \\
\hline Age & .016 & .022 & .000 & 1.016 \\
\hline Education & .832 & .229 & .283 & 1.299 \\
\hline Marital status & .542 & .504 & .196 & 2.248 \\
\hline Clerk & .810 & .627 & .192 & 1.182 \\
\hline Monthly income & .168 & .128 & .648 & .902 \\
\hline Understanding level & -.103 & .225 & .683 & 1.291 \\
\hline Labor contract & .256 & .625 & .681 & 1.307 \\
\hline Management & .268 & .651 & .290 & 1.250 \\
\hline Financial burden & .223 & .211 & .049 & .010 \\
\hline Profession & & & 0.19 & 5.788 \\
\hline Sources & & & .001 & 24.999 \\
\hline Sources (1) & 2.756 & .751 & .135 & 25.567 \\
\hline Sources (3) & 3.219 & .985 & .016 & 5.656 \\
\hline Worries & & & .049 & 5.939 \\
\hline Worries (1) & 3.241 & 1.341 & .058 & \\
\hline Worries (4) & 1.733 & .880 & & \\
\hline Worries (5) & 1.782 & .941 & & \\
\hline
\end{tabular}

insurance. In the "procession" item, manufacturing industry pass the significance test of 0.05 level, we analyze that migrant workers engaged in manufacturing industry are mostly clerks in the enterprise; besides, manufacturing industry has high stability, it needs certain skills to earn their only finance income, so they attach greater importance to their works and are more willing to participate in unemployment insurance; while in the period of time in the future, "endowment", "fall ill", "can't afford the tuition" and other problems will hinder the migrant workers to participate in unemployment insurance.

\section{Analysis of maternity insurance}

In the data analysis of Table 7 we can find that "education" pass the significance test of 0.01 level, "sources (1)" and "sources (3)" both pass the significance test of 0.05 level, some parts of "worries" also pass the significance test of 0.1 level, the coefficient is positive.

From the data we analyze that the main influencing factors of participating in maternity insurance is the understanding level, the higher the education is, the more credibility the sources have, the easier migrant worker participating in maternity insurance. Since migrant workers are conservative relatively and they don't know much about maternity insurance, so the unit and government should conduct more propaganda and let more migrant workers benefit from it.

\section{Analysis of medical insurance}

From the data analysis of Table 8 we can find that "marital status", "monthly income", "worries (1)" all pass the significance test of 0.1 level and above, the coefficient is positive.

"Married" and "worries (1)" have the significant influence on migrant workers participation in medical insurance. Since the attitude to live of married migrant workers will be more dependable, so they will more focus on unknown risks and unstable factors, pay more attention to the insurances of lives and attend medical insurance; while migrant workers worrying about suffering employment injury will naturally participate in medical insurance, since it's helpful once they get hurt, so the migrant worker will positively attend the medical insurance. The higher the monthly income is, the bigger probability they choose to attend the medical insurance. The result explains that current insurance cost is higher than the amount that migrant workers can afford, so on the one hand, the government agencies should increase the income of migrant workers, on the other hand, the government should formulate reasonable insurance cost standard. 
Table 8. Regression analysis of medical insurance

\begin{tabular}{|c|c|c|c|c|}
\hline Explanatory variable & Regression coefficient(B) & Standard error(S.E.) & Significance(Sig.) & Power(exp(B)) \\
\hline \multicolumn{5}{|l|}{ Medical insurance } \\
\hline Gender & .082 & .322 & .798 & 1.086 \\
\hline Age & -.023 & .018 & .197 & .977 \\
\hline Education & -.066 & .183 & .718 & .936 \\
\hline Marital status & 1.041 & .434 & .016 & .353 \\
\hline Clerk & .322 & .531 & .544 & 1.380 \\
\hline Monthly income & .184 & .105 & .078 & .832 \\
\hline Understanding level & .264 & .192 & .169 & 1.302 \\
\hline Labor contract & .316 & .551 & .566 & 1.372 \\
\hline Management & -.803 & .681 & .238 & .448 \\
\hline Financial burden & .006 & .174 & .973 & 1.006 \\
\hline Profession & & & .103 & \\
\hline Sources & & & .163 & \\
\hline Worries & & & .434 & \\
\hline Worries (1) & 2.444 & 1.311 & .062 & 11.514 \\
\hline
\end{tabular}

\section{CONCLUSION AND SUGGESTION}

\section{Main Conclusion}

From the investigation and analysis of migrant workers' participation in social insurance in Lanzhou, we can find that the percentage of participation in social insurance is much higher than 2013, but migrant workers who don't participate it still take up the most, so promoting migrant workers participating in social insurance is still a hard task. Besides, the percentage of people attending employment injury insurance and unemployment insurance is low, and employment injury insurance is very importance for migrant workers engaged in construction industry, so it's urgent to expand the coverage of social insurance among migrant workers and safeguard fied rights of migrant workers. After the regression analysis of employment injury insurance, endowment insurance, unemployment insurance, maternity insurance and medical insurance, we conclude the influencing factors of social insurance as following:

\section{Influencing factors on the individual level}

From the regression analysis of 13 variables in employment injury insurance, endowment insurance, unemployment insurance, maternity insurance and medical insurance, we can find that individual factor will affect one's decision, including age, gender, education, marital status and so on. However, from the regression analysis of these 5 insurances we can also conclude that, these individual factors don't have significant influence, the greatest influence among these factors is education.

\section{Influencing factors on the unit level}

From the comparative analysis of factors of individual level, we can find that influencing factors in the unit level not only show the high significance, but also have a great effect on migrant worker's choice. Influencing factors in unit level are industry types, sign the labor contract, and clerk and so on. On the regression analysis of these 5 insurances we can find that, the significance of these factors is higher than individual level, factors in unit level have the greater influence in migrant worker's choice. It reflects that in the situation of market economy, unit's supply willingness will greatly influence migrant worker's participation.

\section{Influencing factors on the design of legal system level}

On the process of choosing variable includes some variables lied in legal system level, such as the sources, understanding level and so on. From the regression analysis of these 5 insurances, we can find that understanding level, sources and other factors will influence migrant worker's choice in participating in social insurance in Lanzhou, the more regular and overall the source is, the deeper the understanding level is, the more possible migrant workers will choose to participate in social insurance. Therefore, the seriousness of the application of current social security system, the low insured rate of social insurance reflects the insufficiency of the system design, the coverage, and the propaganda, so it blocks the sources of migrant workers to understand the policy, the understanding level is too low to migrant workers to attend social insurance positively. 


\section{Countermeasures and Suggestions}

Based on the analysis of present situation of migrant workers' participation in social insurance and influencing factors of different types of insurance, this article put forward the following suggestions:

(I). As for the low insured rate of employment injury insurance and unemployment insurance, we think on the one hand, government agencies should keep on broadcast, supervise and punish, on the other hand, as for the features of high mobility and the frequent change of service subject to formulate corresponding strategy. We can set up electronic information files for migrant workers according to the situation of participating the insurance to improve the flexibility of participating the insurance and simplify the procedure of participation. At the same time, we should constantly improve the design of system of unemployment insurance, establishing the unemployment insurance system which can cover most of the migrant workers as soon as possible.

(II). From the regression analysis, we can find that the understanding to social insurances has a huge influence on the decision of migrant workers. For that reason, we should not only keep on broadcasting, but also formulate suitable strategy for migrant workers. At least, we should pay attention to the following tips: first, adopting more explanation and video to broadcast relevant policies; second, adopting more common words to broadcast and explain to the public.

(III). Standardize the system of enterprises. Besides making a suitable adjustment in individual level and legal system level, we should standardize enterprises' employing system, carry out < Labor Contract Law> step by step, and supervise the signature and performance of the labor contract. At the same time, the unit should decrease the variation of the employment and try to supply a stable working environment and post for employees.

\section{ACKNOWLEDGEMENTS}

This work is supported by grants from the Social Sciences Planning Foundation of Ministry of Education (15YJA630097 and 16XJA630002), Fundamental Research Funds for the Central University from Lanzhou University (17LZUJBWZD011 and 17LZUJBWZY034), Philosophy and Social Sciences Planning Foundation of Lanzhou (17-008D).

\section{REFERENCES}

Fei, G., \& Zhanxin, Z. (2013). The social insurance of floating population under the new policy of migrant workers: data from China's four main cities. Population Study, (3).

Hangsheng, Z., \& Dayong, H. (1994). Focus on and develop the social insurance career of migrant workers- an important problem on the process of social transformation. Academic Communication, (05), 122-128.

He, C., Chao, L., \& Jianhua, F. (2009). The research on interests struggle behavior of migrant workers whose interests are damaged- on the basis of research on enterprises of Pearl River Delta. Sociological research, (1).

Jia, L., \& Xuejing, L. (2013). The fairness of vulnerable group participation in medical insurance and analysis of its influencing factors. East China Economic Management, (02), 28-32.

Jiaojiao, Y. (2012). The existing problems and the solutions of migrant worker's social insurance issue. Modern Business, (15).

Jinfei, L., \& Shengping, Z. (2013). The willingness of participating in social insurance and its influencing factors of new generation of migrant workers. Chongqing Social Science, (10).

Nan, L. (2010). Investigation report on situation of migrant workers' participation in social insurance in Sanshui Area, Foshan. Rule of law and society, (21).

Ning, G. (2013). The situation and countermeasure analysis of migrant workers' social insurance issue. People Forum, (11).

Ningyang, H., \& Meng, G. (2010). The willingness of trans-provincial transformation and analysis of family factors of migrant workers- on the basis of the regression model of household survey. Rural Survey of China, (2).

Park, J., Chu, H.-E., \& Martin, S. N. (2016). Exploring how Korean teacher's attitudes and self-efficacy for using inquiry and language based teaching practices impacts learning for culturally and linguistically diverse students: Implications for science teacher education. Eurasia Journal of Mathematics, Science $\mathcal{E}$ Technology Education, 12, 7.

Rong, L., \& Peng, L. (2005). Factor analysis of social insurance system design of migrant workers-take practice in Chengdu as an example. Population Research, (02), 76-79.

State Council of the PRC. (28 March 2008). Some opinions on solving the problems of migrant workers from the State Council. 
State Statistical Bureau. (2015). National Investigation Report of Migrant Workers in 2013. Retrieved from http://www.stats.gov.cn/tjsj/zxfb/201405/t20140512_551585.html

Tao, W., Yingjun, Z., \& Hao, C. (2005). The rational thinking on city migrant workers' social security issue. Rural Economy, (03), 84-87.

Wang, Y.-P. (2016). A Study on Kinmen Resident's Perception of Tourism Development and Culture Heritage Impact. Eurasia Journal of Mathematics, Science \& Technology Education, 12, 12.

Wei, L. (2013). The reviews of the social security issue of migrant workers. Review of Economic Research, (6).

Yangti, H. (2009). The research on influencing factors of migrant workers' participation in social insurance. Statistical research, (04).

Yiqiao, Z. (2004). The discussion of solving migrant workers' social security issue. Journal of Hunan Agricultural University (JCR-SSCI), (02), 19-22.

Yonghong, G. (2010). Empirical analysis on migrant workers' willingness to participate in social insurance. Journal of Central China Normal University (Humanities and Social Sciences Edition), (03).

Zengyang, X., \& Shengxiang, J. (2015). The research on the influencing factors of migrant workers' tendency to safeguard legal rights by non-institutionalized method- on the basis of analysis from 1554 samples of migrant workers around the world. China Soft Science, (1), 67-76.

Zhaiwen, P., \& Libin, Q. The difficulty and outlet of social security of migrant workers-from the perspective of policy analysis. Gansu Social Science, (6).

Zhixian, L. (2005). The status quo, loss reason and the thinking of countermeasures of social security rights of migrant workers. Journal of the Party School of the Central Committee, (04), 79-83.

Zhuli, W. (2012). The situation and analysis of influencing factors of social insurance of migrant workers-on the basis of the survey data from Jiangsu Province. Xue Hai, (02).

\section{http://www.ejmste.com}

